\title{
Grand Challenges in Evolutionary Sociology and Biosociology
}

\author{
Rosemary L. Hopcroft* \\ University of North Carolina at Charlotte, Charlotte, NC, USA
}

Keywords: evolutionary sociology, biosociology, sociobiology, sociology, genes, hormones, evolution

Scholars in the area of Evolutionary Sociology and Biosociology explicitly seek to examine the interplay of social and environmental factors with evolved biological factors and its implications for social behavior. It is a broad area covering a wide array of research topics and methodologies. Neurosociologists in the area describe the neural circuitry underlying social processes, such as empathy, understanding, and the social creation of the self and self-identity [e.g., Franks (2010)]. Other researchers examine the effects of our evolutionary history on emotional processes that influence social behaviors [e.g., Turner (2007)] and the implications for humans of comparative primatology [e.g., Turner and Maryanski (2008)]. There are researchers examining the role of stress hormones on life course events and the effects of other hormonal levels (e.g., testosterone) on social behaviors as well as the reciprocal effect of social situations on hormonal states [e.g., Mazur (2004)]. Other researchers examine the correlation between genes and social behaviors [e.g., Guo et al. (2008)] and how environments influence gene expression (epigenetics). Researchers using the techniques of behavioral genetics apportion the percentage of variation in social behaviors that can be attributed to genetic factors [e.g., Kohler et al. (1999)]. Some biosociologists examine how aspects of human appearance including voice, body, and face influence social interactions [e.g., Gregory and Webster (1996) and Mueller and Mazur (1996)]. Others test hypotheses drawn from evolutionary biology (e.g., the Trivers-Willard hypothesis, the effects of status on fertility behavior) on aggregate social outcomes [e.g., Hopcroft (2005) and Fieder and Huber (2007)].

The area is not without controversy within sociology and evolutionary sociology in particular is not accepted by many sociologists, which is one of the greatest challenges the area faces at present. Although the founders (including Durkheim, Marx, and Mead) did not disavow a role for biology in the newly created discipline of sociology, the subsequent hijacking of biology by Social Darwinists and others for racist and sexist causes, and the horrendous results over the course of the twentieth century have tarnished the enterprise of incorporating biology into sociology. Yet as the founders realized, there is nothing antithetical to the mission of sociology than incorporating biology into sociology - the scientific study of the group. The biological nature of humans is in fact the sine qua non of the discipline, as without the human biological predisposition toward sociality, there would be no need for a discipline that focuses on the emergent properties of the human social group.

For sociology to progress as a social science, it is important to reconnect sociology with biology and the rest of the life sciences, as all sciences build on the sciences that exist at a lower level of analysis - biology on chemistry, chemistry on physics, and so on. But the lessons of history must be learned. I see three problems facing the area of evolutionary sociology and biosociology that researchers in the area must address before the area can fully develop within sociology itself. The three problems are confusion about levels of analysis and the implications of the findings of evolutionary sociology and biosociology for individuals; the meaning of causality in the social sciences and the nature of sociological explanation; and last, confusion about the moral implications of a biologically based general social science. Researchers in the area must deal with these challenges and help resolve the problems they create before the area can progress substantively.

First, there is confusion about levels of analysis. Sociology as a discipline focuses on the group, so evolutionary sociologists and many biosociologists do research at the aggregate level. That is, 
the findings of the research are usually statistical in nature and apply at the aggregate level only. For the sake of illustration, let us say a researcher finds a correlation between a gene variant and a social behavior. This means that at the level of the group, given the environment of the individuals in that group, those individuals with the gene variant are also more likely to display the social behavior than those without that gene variant. This finding does not mean that every individual with that gene variant displays that social behavior. Genes and their variants only predispose individuals to certain traits and behavior, whether or not the trait in question develops depends on the particular individual and his or her history, as well as the individual's environment and situation. This is as true for genes for physical features, such as height or eye color, as it is for genes for social behaviors. Indeed, much of the current genetic research in biosociology is involved with determining the interactions of social and other environments with gene expression and which environments are more likely to lead to an individual with that gene variant to display that social behavior.

The correlation between a gene variant and a social behavior does not mean that in every conceivable environment (both material and social) in the present or in the future, individuals with that particular gene variant will be more likely to display that particular social behavior. So, a gene that promotes aggression, say, may predispose individuals to aggression in the contemporary environments included in the particular study, but not in different environments not included in the study, or in future environments.

This probabilistic nature of gene expression, as well as the importance of the environment in gene expression, is difficult for many people to grasp fully. Many take the correlation of a gene with a social behavior as evidence that this gene "causes" the behavior in that if a person has that gene, he or she will necessarily display that behavior. It is true that the gene may help to cause the behavior, but we will never know that for sure without the use of experimental methods which, for moral and ethical reasons, can often not be used with human subjects (although experiments are often possible particularly in some areas of biosociology). As always, correlation is not causation, and researchers have to make this clear when they do this kind of research.

Then, of course, there is the fact that humans are conscious, thinking, and sentient beings who can decide how to behave for whatever reason (including cultural factors). For example, we all have a strong desire to eat and a strong sex drive, both of which are evolved traits and have a genetic basis but that does not mean that people cannot go on hunger strikes or become celibate. All of this means that an individual with a particular gene associated with a behavior may decide to prevent him or herself from performing that particular behavior, whatever the circumstances.

The argument I have just made refers to gene variants, but the same argument can be made with other biochemicals, such as hormones, gene-based traits, such as sex, and complex evolved traits (e.g., a particular emotion, traits promoting complex social behaviors such as parenting) for which the genetic basis is as yet unknown. Much of this research finds correlations, not causes. Yet for a science that seeks to explain group behavior and aggregate patterns, even a correlation between a gene or other evolved trait and social behaviors is an important step in the process of developing adequate explanations for social behavior.

Another problem that must be resolved is that some sociologists have difficulty reconciling the fact that people are cultural, thinking beings with our biological nature, and conclude that accepting one means denying the other. They rail against "biological determinism" [e.g., Risman (2001)]. These sociologists assume that sociological theories may explain social behavior with either culture or biology, but not both. It is true that humans can work to actively suppress parts of their nature, as described above, for cultural reasons. Yet it is false to think of culture and biology as mutually exclusive. Human cultures are a result of our biological nature - we evolved to have a culture, so the idea that biology and culture are irreconcilable within sociological theory cannot make sense. Further, our biological nature influences our culture, as demonstrated by the large quantity of human universals that exist in all human societies (Brown, 1991). Once again a part of the problem here may be in understanding the levels of analysis - genes and evolved traits operate on individuals, and culture is an emergent property of an aggregate of individuals. Yet the one does not negate the other, just as the emergent properties of a chemical compound do not negate the properties of the elements of which it is composed. The key is to understand how culture and our universal human nature interact with each other to produce the social behaviors we see.

The last problem facing evolutionary sociology and biosociology within sociology is confusion about the moral implications of a biologically based general social science. Sociology since Marx has been concerned with social justice and social morality, yet misuses of biology in social science have been used to justify some of the worst moral disasters of the twentieth century. It is perhaps understandable that sociologists are unwilling to risk such disasters again. Yet this is once again based on a faulty understanding of evolutionary sociology and biosociology. Evolutionary sociology and biosociology are based on the fact that in their genes and other evolved traits, all humans are more similar than they are different. Genetically all humans share the same genes, with only small differences in gene variants between individuals and between groups (Witherspoon et al., 2007). The biological unity of humanity that underlies evolutionary sociology and biosociology is compatible with most moral codes based on the essential equality of all, including the United Nations Declaration of Human Rights, and most religious codes. Further, it is likely that many of the common social biases that are found cross-culturally - e.g., racial and gender-based biases - have an evolved basis (Banaji and Greenwald, 2013). Understanding how evolved genes and traits influence social behavior (and vice versa) can help us better understand the social world. This I believe is an intrinsically moral enterprise, as suggested by the name given to the period in history when people first attempted it - the Enlightenment.

Once these preliminary disciplinary problems have been resolved, there remain many substantive challenges for an area that is still in its infancy. Researchers have only begun to examine the interactions of genes, environments, and social behaviors, such as aggression, sexual behavior, and delinquency, but there is much more to study. Epigenetics - how social 
environments influence genes themselves is an emerging area of study. One problem facing the expansion of such research is that only a few current sociological surveys (e.g., Add Health, go to http://www.cpc.unc.edu/projects/addhealth) and other studies collect information on individuals genes and/or other biochemicals as well as important sociological information, such as social class, education, and so on - hopefully in the future, the incorporation of such measures into sociological studies will become routine.

Further, the use of evolutionary biology to generate hypotheses and test them in sociology has only just begun. Many sociologists have particular dislike for the sociobiological and evolutionary psychological theories that generate some of these hypotheses. For example, some dislike sociobiologists' concern with ultimate causes, particularly the idea that all organisms including humans "maximize fitness." Yet sociobiologists and evolutionary psychologists make clear that all behavior is context sensitive, and some contexts (such as in modern industrial societies) can mean that the number of offspring are very limited, particularly in a species, such as humans, with a pronounced $K$-strategy of reproduction - meaning high parental investment and comparatively few children born.

Further, sociobiologists note that social status among social species is almost always correlated with reproductive success, and new research shows that to be the case for some measures of status for men (income in particular), if not for women in a variety of advanced industrial societies, repeating the pattern of pre-industrial societies and indeed most primates. The sociobiological hypothesis of a positive relationship between male status and reproductive success was possible to test fully only because of the fortuitous availability of comprehensive data on male fertility from registry data in many European countries [e.g., Fieder and Huber (2007)]. Other sociobiological hypothesis

\section{REFERENCES}

Banaji, M., and Greenwald, A. (2013). Blindspot: Hidden Biases of Good People. New York: Delacorte Press.

Brown, D. E. (1991). Human Universals. New York: McGraw Hill.

Fieder, M., and Huber, S. (2007). The effects of sex and childlessness on the association between status and reproductive output in modern society. Evol. Hum. Behav. 28, 392-398. doi:10.1016/j.evolhumbehav.2007.05.004

Franks, D. (2010). Neurosociology: The Nexus between Neuroscience and Social Psychology. New York: Springer.

Gregory, S. W. Jr., and Webster, S. (1996). A nonverbal signal in voices of interview partners effectively predicts communication accommodation and social status perceptions. J. Pers. Soc. Psychol. 70, 1231-1240. doi:10.1037/0022-3514.70.6.1231

Guo, G., Roettger, M., and Cai, T. (2008). The integration of genetic propensities into social control models of delinquency and violence among male youths. Am. Sociol. Rev. 73, 543-568. doi:10.1177/000312240807300402

Hopcroft, R. L. (2005). Parental status and differential investment in sons and daughters: Trivers-Willard revisited. Soc. Forces 83, 169-193. doi:10.1353/ sof.2005.0035

Kohler, H.-P., Rodgers, J. L., and Christensen, K. (1999). Is fertility behavior in our genes? Findings from a Danish Twin Study. Popul. Dev. Rev. 25, 253-288. doi:10.1111/j.1728-4457.1999.00253.x cannot be tested adequately because of the lack of suitable data. For example, in the U.S., family studies often do not differentiate a person's children according to whether they are a biological child, step child, adopted child, etc., information that is important for testing evolutionary hypotheses. The routine collecting of such measures in sociological surveys that would allow testing of evolutionary hypotheses should be encouraged, certainly before the sociobiological and evolutionary psychological theories that generate them are dismissed out of hand.

Another problem is that contemporary sociological research tends to be quite parochial - concerned with one region and population and its concerns. Social surveys tend to collect information on that region and population alone. Yet clearly, cultures do vary across regions, and for full understanding of the interaction between biological and social factors, cross-cultural research is essential. This new section of Frontiers in Sociology, Evolutionary Sociology and Biosociology, is designed to be international in scope. Hopefully, this will serve to encourage collaboration by sociologists and other researchers across borders, and the future collection of high quality, cross-cultural data sets suitable for the testing of evolutionary and biosocial hypotheses.

Evolutionary sociology and biosociology are truly a new frontier in sociology. Like all very new frontiers of knowledge in an academic discipline, it is controversial in some quarters and faces the opposition of sociologists who misunderstand the enterprise, and fear the consequences of its full incorporation into sociology. Yet a biologically informed sociology would be a better sociology - and that is in all sociologists' interests.

\section{AUTHOR CONTRIBUTIONS}

The author confirms being the sole contributor of this work and approved it for publication.

Mazur, A. (2004). Biosociology of Dominance and Deference. New York: Rowman \& Littlefield.

Mueller, U., and Mazur, A. (1996). Facial dominance of West Point cadets as a predictor of later military rank. Soc. Forces 74, 823-850. doi:10.2307/2580383

Risman, B. J. (2001). Calling the bluff of value-free science (comment on Udry 2000). Am. Sociol. Rev. 66, 605-611. doi:10.2307/3088926

Turner, J. H. (2007). Human Emotions: A Sociological Theory. New York: Routledge.

Turner, J. H., and Maryanski, A. (2008). On the Origins of Societies by Natural Selection. Boulder, CO: Paradigm Publishers.

Witherspoon, D. J., Wooding, S., Rogers, A. R., Marchani, E. E., Watkins, W. S., Batzer, M. A., et al. (2007). Genetic similarities within and between human populations. Genetics 176, 351-359. doi:10.1534/genetics.106.067355

Conflict of Interest Statement: The author declares that the research was conducted in the absence of any commercial or financial relationships that could be construed as a potential conflict of interest.

Copyright $(2016$ Hopcroft. This is an open-access article distributed under the terms of the Creative Commons Attribution License (CC BY). The use, distribution or reproduction in other forums is permitted, provided the original author(s) or licensor are credited and that the original publication in this journal is cited, in accordance with accepted academic practice. No use, distribution or reproduction is permitted which does not comply with these terms. 